\title{
Effect of Diet Therapy Program on Dietary Knowledge and Practice of Elderly Patients on Regular Hemodialysis
}

\author{
Eman Shokry Abd Allah", Eman El-Shahat El-Sayed Oraby ${ }^{2,}$,, Rasha Gad Ibrahim³ \\ ${ }^{1}$ Community \&Gerontological-Nursing, Community Health Nursing, Faculty of Nursing, Zagazig University, Zagazig City, Egypt \\ ${ }^{2}$ Public Health and Community Medicine, Faculty of Medicine, Zagazig University, Zagazig City, Egypt \\ ${ }^{3}$ Community Health Nursing, Faculty of Nursing, Mansura University, Mansura city, Egypt
}

\section{Email address:}

dr.eman.elshahat@gmail.com (E. E. E. Oraby)

\section{To cite this article:}

Eman Shokry Abd Allah, Eman El-shahat El-Sayed Oraby, Rasha Gad Ibrahim. Effect of Diet Therapy Program on Dietary Knowledge and Practice of Elderly Patients on Regular Hemodialysis. American Journal of Nursing Science. Vol. 4, No. 3, 2015, pp. $131-137$.

doi: 10.11648/j.ajns.20150403.23

\begin{abstract}
The identification and proper management of risk factors for chronic renal diseases is a public health priority. Diet Nutrition program on elderly patients with uraemia on dialysis plays an important role in the process of treatment, decreasing complications and improving quality life of patients. The aim of this study was to assess the effectiveness of diet therapy program on dietary knowledge and practice of elderly patients on regular hemodialysis. Design: An interventional study was used. Setting: The study was conducted at the hemodialysis units of the Urology and Nephrology Centers at Zagazig University Hospitals. Sample: The study sample consisted of 90 elderly patients on regular hemodialysis who received the diet therapy program. Tools: Data was collected through: (1) An interviewing questionnaire to assess sociodemographic characteristics of patients, their dietary knowledge and practice before and after diet therapy program; (2) physical assessment checklist to assess abnormal physical findings of patients before and after intervention. Results: the elderly patients under hemodialysis have deficient dietary knowledges and practices. The implementation of the diet therapy program was effective in improving dietary knowledge and practices of elderly patients. The total knowledge and practice of the patients showed statistically significant improvements after the intervention ( $61.1 \%$ and $67.8 \%$ )respectively after the intervention compared with $18.9 \%$ and $23.3 \%$ respectively before intervention $(\mathrm{p}<0.001)$. Recommendations: Diet therapy programs need to be a priority on management of elderly patients under regular hemodialysis.
\end{abstract}

Keywords: Diet Therapy Programs, Elderly Nutrition, Elderly Patients Under Hemodialysis

\section{Introduction}

The identification and treatment of risk factors for chronic renal diseases is a public health priority since renal failure is a serious irreversible problem (Huang et al., 2014) Renal replacement therapy including hemodialysis, peritoneal dialysis, and renal transplantation are successful modalities for supporting patients with renal failure or endstage renal disease (ESRD). Dialysis is typically needed when approximately $90 \%$ or more of kidney function is lost (Sathishbabu and Suresh, 2012). Hemodialysis in elderly patients has important differences from younger patients. The mortality benefit of initiating HD is likely reduced in patients with the most comorbidities (McDonald et al., 2009).

Faulty dietary practices such as high dietary acid intake could have a negative impact and can lead to progression of the chronic renal disease (Kanda et al, 2014). On the other hand, an important role of tailoring dialysis and dietary regimen in improving the prognosis of elderly patients with chronic renal disease and undergoing hemodialysis has been shown (Piccoli et al, 2014). Hence, nutrition in hemodialysis is very important in decreasing complications and improving patient's quality life (Mahan et al., 2012).

Nephrology nurses can lead the way to implementing numerous proactive interventions before, during, and after hospitalization of patients on HD. Nurses often have more contact with patients than other clinical personnel and are in an ideal position to optimize assessment, management, and monitoring of clinical issues likely to affect patients on 
dialysis, including malnutrition status. Nephrology nurses are encouraged to apply the principles of successful nursing models currently in place to develop site-specific practices and processes to improve quality of care before, during, and after hospitalization of patients on dialysis (Castner, 2011). Moreover, the role of nurses in nutritional screening and counseling of these patients has been shown to have positive impacts (Bennett et al, 2013).

The elderly have an increased susceptibility to disease and chronic illness and there are a variety of other social and physiological influences that may affect their diet. These patients are at a higher risk for nutritional deficiencies and special monitoring or intervention may be needed. Hence, nutrition programs play an important role in the process of their treatment. Therefore the aim of this study was to assess the effectiveness of diet therapy program on dietary knowledge and practice of elderly patients on regular hemodialysis. The research hypothesis was that: Application of diet therapy program for elderly patients on regular hemodialysis improves their dietary knowledge and practice.

\section{Subjects and Methods}

Research design and setting: An interventional study was conducted at the hemodialysis units of the Urology and Nephrology Center at Zagazig University.

Subjects and sample: The study sample consisted of 90 elderly patients on hemodialysis. Inclusion criteria: patients $\geq 60$ years, willing to participate in the educational program, renal impairment due to renal causes not associated with chronic disease. Exclusion criteria $:<60$ years, bed ridden, Unable to pursue the educational program due to physical or psychological ailments. Renal impairment associated with chronic disease. Sample size was calculated using Epi-Info software (version 3.5.3) (Dean et al., 2005), assuming that the mean overall nutrition knowledge 3.2 (McClelland, 2013) at 80\% power and 95\%CI. We assume that diet therapy program will change the mean knowledge to 3.6; the estimated sample was 90 elderly patients. Sample technique: simple random sample, after doing sampling frame (elderly patients registered in hemodialysis units of the Urology and Nephrology Centers at Zagazig University Hospitals), selection depend on random tables generated by computer.

Tools of data collection:

1):- Interview questionnaire sheet: This consisted of the following parts:

Part I: This was for patient's socio-demographic characteristics as age, education, marital status, occupation, income, residence etc.

Part II: This part covered patients' personal and health habits as smoking, physical activity, etc. It also included patient's medical history, number of medications, and the duration of hemodialysis.

Part III: This part was intended to assess patient's dietary knowledge before and after diet therapy program. It included a series of open and closed true/false questions covering areas of general nutrition, nutrition of elderly, fluid requirements with dialysis, dietary requirements with dialysis, and food preparation.

- Part IV: This was concerned with patient's dietary practices as self-reported before and after the diet therapy program. It included questions about the number of meals/day, following dietary regimen after dialysis, proper use of fat, salt, animal proteins, canned food, and soda, and change of regimen before and after session.

Scoring: the knowledge and practice items reported to be correct were scored " 1 " and the items not correct were scored "0". For each area, the scores of the items were summed-up and the total divided by the number of the items, giving a mean score for the part. These scores were converted into a percent score. The knowledge and practice were considered satisfactory if the percent score was $50 \%$ or more and unsatisfactory if less than $50 \%$.

2):- Physical assessment checklist: This was prepared by the researchers to collect data regarding the changes in physical signs in patients before and after the intervention. It included assessment of patient's dependence in mobility, subnormal subcutaneous fat, lower limbs edema, and pressure ulcers. It also included pre -dialysis session weight and post dialysis to assess fluid dependent weight. The tools were face and content validated through experts' opinions. This was done by five experts: two faculties' members in Community Medicine, two in Medical Clinical Nutrition, and one in Community Healthy Nursing.

Data collection procedures: The fieldwork for this study was carried out through

1):- Assessment phase:

This phase was intended for obtaining baseline data from patients. This helped in the preparation of the educational program, and also as a pre test for further comparison after implementation of the diet therapy program.

The researchers first introduced themselves to patients, and explained to them the purpose of the study briefly. Each patient was interviewed individually using the data collection forms and an oral consent for participation was obtained.

1):- Planning phase:

Based on the results obtained from the assessment phase the researchers designed the diet therapy program content. Accordingly, the program general and specific objectives were set, and the educational materials were prepared for the sessions. The researchers also prepared an illustrated booklet to help participants after the sessions. The contents of the booklet covered general nutrition, nutrition of elderly, fluid requirements with dialysis, dietary requirements with dialysis and dietary practices as number of meals per day, dietary regimen before and after dialysis, Proper use of fat, salt, animal proteins, canned food and soda. The teaching methods included interactive lectures, group discussions, brainstorming, and demonstration-re-demonstration. The teaching media used involved pictures, flipchart, posters, and handouts, in addition to the program booklet prepared by the researchers. The program sessions were as follows: 
First session: This session included an orientation to the program objectives and its procedures. This was followed by an introduction to the urinary system anatomy and physiology, definition, causes and treatment of renal failure.

Second session: covered important issues related to the nutrition therapy for patients undergoing hemodialysis as general nutrition, Nutrition of elderly, Fluid requirements with dialysis, dietary requirements with dialysis, numbers of meals per day, dietary regimen after dialysis and Proper use of fat, salt, animal proteins, canned food and soda.

Third session: covered the most common nutritional problems associated with renal failure, with emphasis in anemia definition, causes, prevention and control.

Fourth session: covered the signs of high level of potassium, its sources and how to control it.

Fifth session: covered the sign of increased level of phosphorus, its sources, and how to control it.

Sixth session: covered how to control thirst without use of excess water.

2):- Implementation phase:

The diet therapy program was implemented to the patients in the study group in small groups. It was divided into six educational sessions. To ensure that the patient understands the program content, each session was started by a summary of what was given through the previous session, followed by elaboration of the objectives of the new one. The researcher used simple language with no scientific terms to suit the educational level of the patients. Motivation and reinforcement techniques as praise and recognition during the sessions were used to enhance active participation.

3):- Evaluation phase:

Evaluation of the effect of the health education intervention carried out through posttest after two months from intervention using the same data collection forms as in the pre-test by comparing result of pre and post test.

Ethical consideration:

All subjects in this study will undergo complete personal data after taking their consent and confidentiality of information is assured.

-Administrative design:

Official permissions will be obtained from the scientific ethical committee of the community Medicine department. An official permission letter will be obtained from Faculty of Medicine, Zagazig University to hemodialysis units of the Urology and Nephrology Centers. The title and objectives of the study will be explained to them to ensure their cooperation. An official permission will be obtained from (IRB) An institusional reviewing board at the faculty.

Statistical analysis: Data entry and statistical analysis were done using SPSS 18.0 statistical software package. Data were presented using descriptive statistics in the form of frequencies and percentages for qualitative variables, and means and standard deviations and medians for quantitative variables. Comparison between results of pre and post test was done using Mc-Nemar chi-square test and paired t test.
Statistical significance was considered at $\mathrm{p}$-value $<0.05$.

\section{Results}

Figure 1 shows that $90 \%$ of patients, their ages were less than 70 years while, $10 \%$ of them $\geq 70$ years old, $64.4 \%$ of them were males while, $35.6 \%$ of them were females, $84.4 \%$ of them were married while, $15.6 \%$ of them unmarried, most of them $(73.3 \%)$ were of moderate socioeconomic status while $6.7 \%$ of them were of high socioeconomic status (we calculate socioeconomic status from education, occupation, income and crowding index).

As regards the medical history of patients, table 1 demonstrates that $78.9 \%$ of patients were less than 5 years on hemodialysis with median of 4 years. Most of them $(86.7 \%)$ take $\leq 10$ medications per day. The majority of the patients $(72.2 \%)$ reported no change in their weight as regard Pre -dialysis session weight and post dialysis and $66.7 \%$ of them never smoke while $15.6 \%$ of them were current smokers.

The dietary knowledge of the patients showed statistically significant improvements after the intervention as presented in Table 2. This was revealed in all areas of knowledge especially regarding fluid requirements with dialysis in which $75.6 \%$ of the patients had satisfactory knowledge in post test compared with $18.9 \%$ in pre test $(\mathrm{p}<0.001)$. Also, the mean knowledge scores regarding nutrition with hemodialysis improved in post test(3 $\pm 1.4)$ compared to mean knowledge scores in pre test $(1 \pm 0.5)$ with statistically significant difference $(\mathrm{p}=0.031)$, and total satisfactory knowledge increase from $18.9 \%$ in pre test to $61.1 \%$ in post test with statistically significant difference $(\mathrm{p}<0.001)$.

Table 3 shows that there were significant improvement in all areas of dietary practices among patients before and after the intervention especially regarding proper use of fat ,salt, animal proteins , canned food and soda in which $(76.8 \%$, $75.6 \%, 77.8 \%, 70 \%$ and $65.6 \%$ ) respectively of the patients had satisfactory dietary practice in post test compared with $(31.1 \%, 34.4 \%, 18.9 \%, 21.1 \%$ and $20 \%)$ respectively in pre test $(\mathrm{p}<0.001)$. also, the mean practice score improved in post test $(6.8 \pm 3)$ compared to mean practice scores in pre test $(3 \pm 1.2)$ with statistically significant difference $(p=0.016)$. Also, total satisfactory practice increase from $67.8 \%$ in post test compared to $23.3 \%$ in pre test $(\mathrm{p}<0.001)$.

Concerning the pre-intervention physical assessment findings, Table 4 indicates that $75.6 \%$ of patients were having subnormal cutaneous fat also, $77.8 \%$ of patients were having lower limbs edema. After the intervention, these physical abnormalities had decreased to be $46.7 \%$ subnormal coetaneous fat and 50\% lower limbs edema with statistically significant differences $(\mathrm{p}<0.001)$.In total, $60 \%$ of the patients after the intervention were having abnormal physical findings compared to $97.8 \%$ of those before the intervention $(p<0.001)$. Moreover, they had significantly lower mean of the number of physical anomalies $(0.7 \pm 0.3)$ in comparison with pre $(2.1 \pm 0.8)(\mathrm{p}<0.001)$. 


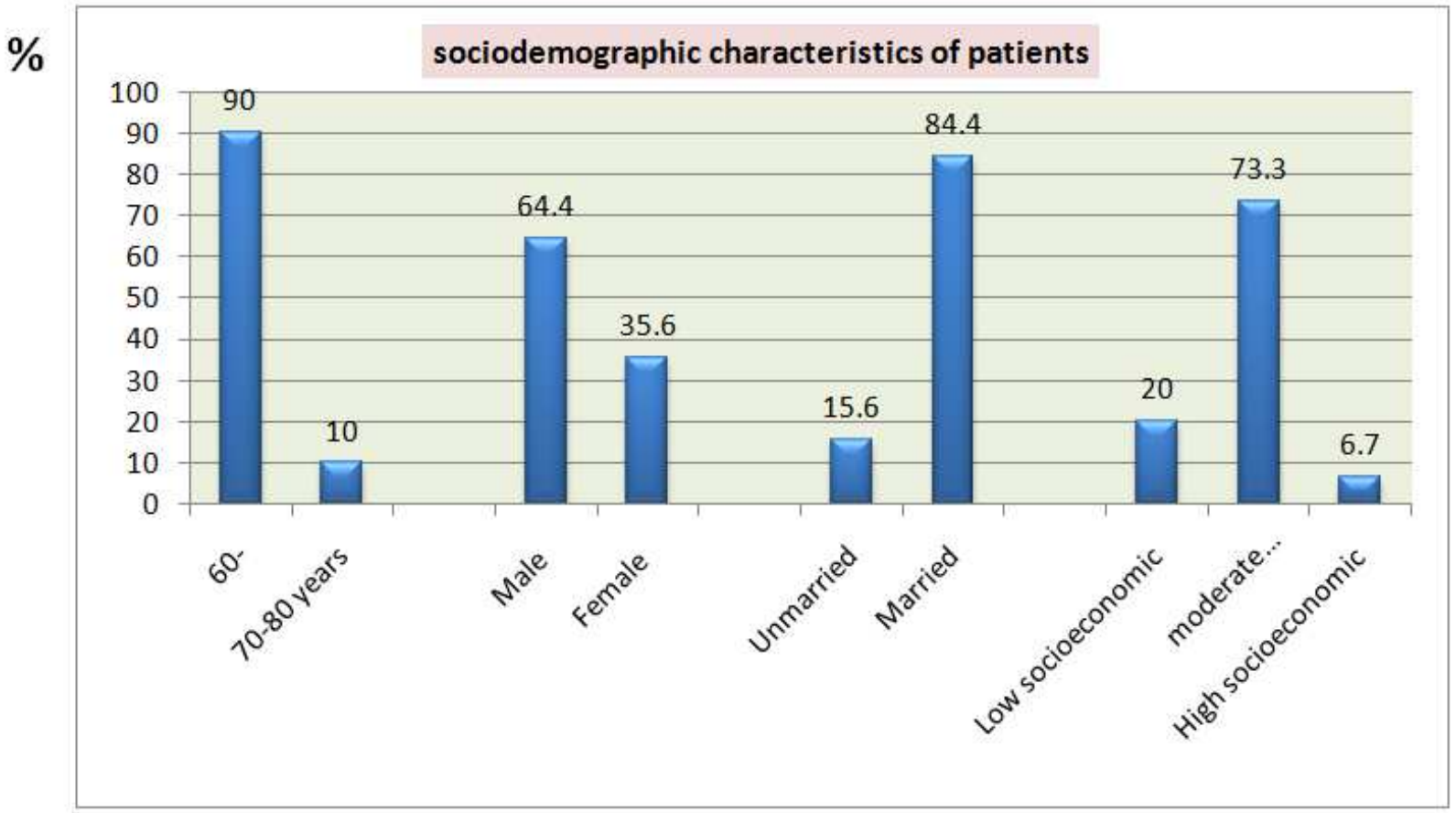

Figure (1). Sociodemographic characteristics of studied patients.

Table (1). Medical history of studied patients.

\begin{tabular}{lll}
\hline & (No. $=\mathbf{9 0}) \mathbf{N o .}$ & \% \\
\hline Duration of hemodialysis (years): & & 78.9 \\
$<5$ & 71 & 21.1 \\
$\geq 5$ & 29 & \\
Range & $4-12.0$ & \\
Mean \pm SD & 4.00 & \\
Median & & 86.5 \\
Number of medications per day: & 78 & 13.3 \\
$\leq 10$ & 12 & 72.2 \\
$>10$ & & 27.8 \\
Pre -dialysis session weight and post dialysis & 65 & 66.7 \\
No change & 25 & 17.8 \\
change & & 15.6 \\
Never & 60 & 16 \\
Past & 14 & \\
Current & & \\
\hline
\end{tabular}

Table (2). Satisfactory dietary Knowledge among patients before and after the intervention (No. $=90$ ).

\begin{tabular}{|c|c|c|c|c|c|}
\hline & \multicolumn{2}{|c|}{ Pre (No. $=90)$} & \multicolumn{2}{|c|}{ post $($ No. $=90)$} & \multirow{2}{*}{ p.value } \\
\hline & No. & $\%$ & No. & $\%$ & \\
\hline \multicolumn{6}{|l|}{ Satisfactory knowledge $(\geq 50)$ : } \\
\hline General nutrition & 20 & 22.2 & 63 & 70.0 & $<0.001^{* *}$ \\
\hline Nutrition of elderly & 19 & 21.1 & 59 & 65.6 & $<0.001^{* *}$ \\
\hline Fluid requirements with dialysis & 17 & 18.9 & 68 & 75.6 & $<0.001^{* *}$ \\
\hline Dietary requirements with dialysis & 18 & 20.0 & 63 & 70.0 & $<0.001^{* *}$ \\
\hline -Total satisfactory knowledge $(\geq 50)$ & 17 & 18.9 & 55 & 61.1 & $<0.001^{* *}$ \\
\hline \multicolumn{6}{|l|}{-Total knowledge scores } \\
\hline Range & $0-5$ & & $0-5$ & & \\
\hline Mean \pm SD & $1.1 \pm 0.5$ & & $3.1 \pm 1.4$ & & $0.031^{*}$ \\
\hline
\end{tabular}

(*) Statistically significant at $\mathrm{p}<0.05$ 
Table (3). Satisfactory dietary practices among patients before and after the intervention.

\begin{tabular}{|c|c|c|c|c|c|}
\hline & \multicolumn{2}{|c|}{ Pre $($ No. $=90)$} & \multicolumn{2}{|c|}{ post $($ No. $=90)$} & \multirow{2}{*}{ p-value } \\
\hline & No. & $\%$ & No. & $\%$ & \\
\hline -No. of meals/day & 23 & 25.6 & 61 & 67.8 & $<0.001^{\text {** }}$ \\
\hline -Follow dietary regimen after dialysis & 20 & 22.2 & 58 & 64.4 & $<0.001^{* *}$ \\
\hline \multicolumn{6}{|l|}{-Proper use of: } \\
\hline Fat & 28 & 31.1 & 69 & 76.8 & $<0.001^{\text {*** }}$ \\
\hline Salt & 31 & 34.4 & 68 & 75.6 & $<0.001^{\text {** }}$ \\
\hline Animal proteins & 17 & 18.9 & 70 & 77.8 & $<0.001^{* *}$ \\
\hline Canned food & 19 & 21.1 & 63 & 70.0 & $<0.001^{\text {** }}$ \\
\hline Soda & 18 & 20.0 & 59 & 65.6 & $<0.001^{* *}$ \\
\hline \multicolumn{6}{|l|}{-Change regimen: } \\
\hline Before session & 21 & 23.3 & 60 & 66.7 & $<0.001^{\text {** }}$ \\
\hline After session & 23 & 25.6 & 64 & 71.1 & $<0.001^{* *}$ \\
\hline -Total satisfactory practice $(\geq 50 \%)$ & 21 & 23.3 & 61 & 67.8 & $<0.001^{\text {** }}$ \\
\hline \multicolumn{6}{|l|}{ Total practice scores } \\
\hline Range & $0-10$ & & $0-10$ & & \\
\hline$($ mean $\pm \mathrm{SD})$ & $3 \pm 1.2$ & & $6.8 \pm 3$ & & $0.016^{*}$ \\
\hline
\end{tabular}

(*) Statistically significant at $\mathrm{p}<0.05$

Table (4). Physical assessment findings among patients before and after the intervention.

\begin{tabular}{|c|c|c|c|c|c|}
\hline & \multicolumn{2}{|c|}{ Pre $($ No. $=90)$} & \multicolumn{2}{|c|}{ post $($ No. $=90)$} & \multirow{2}{*}{ p-value } \\
\hline & No. & $\%$ & No. & $\%$ & \\
\hline \multicolumn{6}{|l|}{ - physical findings: } \\
\hline Dependent in mobility & 44 & 48.9 & 44 & 48.9 & 1.0 \\
\hline Subnormal subcutaneous fat & 68 & 75.6 & 42 & 46.7 & $<0.001^{\text {** }}$ \\
\hline Have lower limbs edema lower limbs edema & 70 & 77.8 & 45 & 50.0 & $<0.001^{\text {** }}$ \\
\hline Have pressure ulcer & 6 & 6.7 & 2 & 2.2 & 0.147 \\
\hline - Total having abnormal physical findings: & 88 & 97.8 & 54 & 60.0 & $<0.001^{* *}$ \\
\hline \multicolumn{6}{|l|}{-No. of abnormal findings } \\
\hline Range & $1-4$ & & $0-3$ & & \\
\hline (mean $\pm \mathrm{SD}$ ) & $2.1=$ & & $0.7 \pm 0.3$ & & $<0.001^{* *}$ \\
\hline
\end{tabular}

(*) Statistically significant atp $<0.05$

\section{Discussion}

Aging poses challenges to maintaining the nutritional status of elderly patients on hemodialysis (Brunori, 2012). The aim of this study was to design, implement, and evaluate the effectiveness of diet therapy program on dietary knowledge and practice of elderly patients on regular hemodialysis. It was hypothesized that after implementation of the diet therapy program, elderly knowledge and practice will be improved.

The patients in the current study had relatively lower duration of hemodialysis, with median of 4years. This is an important factor because a longer duration of hemodialysis may have a negative impact on the elderly nutritional status as well as the dietary practices. In line with this, a study in India revealed that long-term dialysis has significant influences on the mortality and morbidity of patients with chronic renal diseases, and on their nutritional status (Vikrant, 2014).

The present study findings revealed deficient knowledge (18.9\%) among the patients before the intervention, which is an alarming finding. It may reflect a deficiency in the role of caregivers and the healthcare team as educators of these patients. In congruence with this, a study in Italy demonstrated that hemodialysis patients had deficient dietary knowledge, particularly regarding phosphorus (Cupisti et al, 2012).

At the post-intervention phase of the present study there were significant improvements in the knowledge of the patients. This implies the success of the diet therapy program in improving patients' knowledge. The effectiveness of the program could be attributed to the fact that it was custom-tailored to the needs identified among these patients. In agreement with this, a similar success of an educational program in improving chronic renal disease patients' dietary habits was reported in Brazil (Paes-Barreto et al, 2013). The factors that led to success of the present study intervention are similar to those reported by Van Camp et al (2012) in a study in Belgium which included education and behavior reinforcement. Similarly, a study in Taiwan demonstrated the effectiveness of the use of different educational media in improving the knowledge and perceptions of end stage renal diseased patients (Chiou and Chung, 2012).

According to the current study findings, $23.3 \%$ of the patients had adequate dietary practices. This is expected 
given the markedly deficient knowledge among them in addition to the high prevalence of dietary problems. The finding implies a critical need for health educational endeavors for these patients. Meanwhile, after the intervention a majority $(61.1 \%)$ of the patients had adequate total practice. The finding implies the success of the educational intervention in improving patients' dietary practices. This is attributed to the practical part of the educational intervention which was emphasized by the researchers. Moreover, the procedures utilized in administering the program allowed every participant in the study group to interact and express his/her needs and opinions and to practice related skills.

In congruence with the above mentioned present study finding regarding the factors underlying the effectiveness of the educational intervention, Elliot et al (2014) in their study in the United States revealed a similar success in modulating hemodialysis patients' dietary practices. The authors stressed that hemodialysis clinicians and educators may obtain better results with dietary adherence and control if they focus not only toward disease and dietary education but also on understanding modifying factors and individual health beliefs. Moreover, nurse-led educational interventions for hemodialysis patients in China and in Australia demonstrated success in improving the dietary practices of these patients (Shi et al, 2013; Sandlin et al, 2013). Additionally, a study ESRD patients undergoing dialysis in Giza, Egypt demonstrated a significant improvement in their nutritional knowledge following nutritional counselling sessions (Hegazy et al, 2013).

As an objective proof of the current study postintervention improvement in patients' dietary knowledge and practice among the patients in the study group, the results of physical assessment among them demonstrated significant improvements. This provides a further confirmation of the effectiveness of the educational intervention. These improvements in physical examination findings would have a positive impact on these patients' prognosis as reported by Choi et al (2014) in their study in Korea.

\section{Conclusion and Recommendations}

In conclusion, the elderly patients under hemodialysis have deficient dietary knowledge and practice. The implementation of the educational intervention is effective in improving their dietary knowledge and practices. In view of these findings, it is recommended to apply the diet therapy program in similar settings, with more efforts in educating elderly patients on hemodialysis, especially those with low level of education and income and those with dietary problems and abnormal physical findings. These patients also need solving their dietary problems that have a negative impact on their nutritional state, with close physical assessment of any abnormal physical findings. Diet therapy programs need to be a priority on management of elderly patients under regular hemodialysis.

\section{References}

[1] Bennett P.N., Miller M.D., Woodman R.J., Hill K., Murray S., Gleadle J. M. (2013): Nutrition screening by nurses in dialysis. J Clin Nurs.; 22(5-6):723-32.

[2] Brunori G. (2012): [Nutritional status of patients with chronic kidney disease]. [Article in Italian]. G Ital Nefrol.; 29 (Suppl 58): S68-71.

[3] Castner D. (2011): Management of patients on hemodialysis before, during, and after hospitalization: Challenges and suggestions for improvements. Nephrology Nursing Journal; 38(4): 319-330.

[4] Chiou C.P., and Chung Y.C. (2012): Effectiveness of multimedia. interactive patient education on knowledge, uncertainty and decision- making in patients with end-stage renal disease. J Clin Nurs.;21(9- 10):1223-31.

[5] Choi S.J., Kim E.J., Park M.Y., Kim J.K., Hwang S.D. (2014): Does body fat mass define survival in patients starting peritoneal dialysis? Perit Dial Int.;34(4):376-82.

[6] Cupisti A., Ferretti V., D 'Alessandro C., Petrone I., Di Giorgio A., Meola M., Panichi V., Conti P., Lippi A., Caprioli R., and Capitanini A. (2012): Nutritional knowledge in hemodialysis patients and nurses: focus on phosphorus. J RenNutr.; 22(6):541-6.

[7] Dean A.G., Dean J.a., Coulombeir D. and Brendel K.A. 2005: Epi-info version 3.5.3: a window processing data base and statistics program for epidemiology on microcomputers. Center for Disease Control. Atlanta, Georgia, USA.

[8] Elliott J.O., Ortman C., Almaani S., Lee Y.H., and Jordan K. (2014):Understanding the Associations Between Modifying Factors, Individual Health Beliefs, and Hemodialysis Patients' Adherence to a Low-Phosphorus Diet. J RenNutr.Pii; S10512276(14):00158-7.

[9] Hegazy I.S., El Raghy H.A., Abdel-Aziz S.B., and Elhabashi E.M.(2013): Study of the effect of dietary counselling on the improvement of end-stage renal disease patients. East Mediterr Health J.;19(1):45- 51.

[10] Huang Y., Cai X., Zhang J., Mai W., Wang S., Hu Y., Ren H., and Xu D.(2014): Prehypertension and Incidence of ESRD: A Systematic Review and Meta-analysis. Am J Kidney Dis.; 63(1):76-83.

[11] Kanda E., Ai M., Kuriyama R., Yoshida M., and ShiigaiT. (2014):Dietary acid intake and kidney disease progression in the elderly.doi: 10.1159/000358262. Epub 2014 Feb 11.

[12] Mahan K., Escott-Stump S., and Raymond J.L. (2012): Krause's Food and the Nutrition Care Process, 13. Edition, Elsevier.

[13] Marinac D., Josipovic J., and Pavlovic D. (2012): [Age and arterial hypertension in hemodialysis patients]. [Article in Croatian].Acta Med Croatica.;66(3):165-71.

[14] McClelland J .,2013: Nutrition Education Brings Behavior and Knowledge Change in Limited-Resource Older Adults.available on http://www.joe.org/joe/2013april/a1.php

[15] McDonald S.P., Marshall M.R., Johnson D.W., and Polkinghorne K.R. (2009): Relationship between dialysis modality and mortality. J Am SocNephrol; 20: 155-163. 
[16] Paes-Barreto J.G., Silva M.I., Qureshi A.R., Bregman R., Cervante V.F., Carrero J.J., and Avesani C.M. (2013): Can renal nutrition education improve adherence to a low-protein diet in patients with stages 3 to 5 chronic kidney disease? J Ren Nutr.;23(3):164-71.

[17] Piccoli G.B., Guzzo G., Vigotti F.N., Capizzi I., Clari R., Scognamiglio S., Consiglio V., Aroasio E., Gonella S., Veltri A., and Avagnina P.(2014): Tailoring dialysis and resuming low-protein diets may favor 15 chronic dialysis discontinuation: report on three cases. Hemodial Int.;18(3):590-5.

[18] Sandlin K., Bennett P.N., Ockerby C., Corradini A.M. (2013): The impact of nurse-led education on haemodialysis patients phosphate binder medication adherence. J Ren Care.;39(1): $12-8$.

[19] SathishbabuM., and Suresh S. (2012): A study on correlation of serum prealbumin with other biochemical parameters of malnutrition in hemodialysis patient, Int J Biol Med Res; 3(1): 1410-1412.

[20] Shi Y.X., Fan X.Y., Han H.J., Wu Q.X., Di H.J., Hou Y.H., and Zhao Y. (2013): Effectiveness of a nurse-led intensive educational programme on chronic kidney failure patients with hyperphosphataemia: randomised controlled trial. J ClinNurs.; 22(7-8):1189-97.

[21] Van Camp Y.P., Huybrechts S.A., Van Rompaey B., and Elseviers M.M. (2012): Nurse-led education and counselling to enhance adherence to phosphate binders. J Clin Nurs.;21(910):1304-13.

[22] Vikrant S. (2014): Long-term clinical outcomes of peritoneal dialysis patients: 9-year experience of a single center from north India. Perit Dial Int.;34(4):426-33. 